\title{
Stress and the Aging Hippocampus
}

\author{
Bruce S. McE wen
}

Harold and Margaret Milliken Hatch Laboratory of Neuroendocrinol ogy, Rockefeller University, 1230 York Avenue, New York, New York 10021

\begin{abstract}
The "glucocorticoid cascade hypothesis" of hippocampal aging has stimulated a great deal of research into the neuroendocrine aspects of aging and the role of glucocorticoids, in particular. Besides strengthening the methods for investigating the aging brain, this research has revealed that the interactions between glucocorticoids and hippocampal neurons are far more complicated than originally envisioned and involve the participation of neurotransmitter systems, particularly the excitatory amino acids, as well as calcium ions and neurotrophins. New information has provided insights into the role of early experience in determining individual differences in brain and body aging by setting the reactivity of the hypothalamopituitary-adrenal axis and the autonomic nervous system. As a result of this research and advances in neuroscience and the study of aging, we now have a far more sophisticated view of the interactions among genes, early devel opment, and environmental influences, as well as a greater appreciation of events at the cellular and molecular levels which protect neurons, and a greater appreciation of pathways of neuronal damage and destruction. While documenting the ultimate vulnerability of the brain to stressful challenges and to the aging process, the net result of this research has highlighted the resilience of the brain and offered new hope for treatment strategies for promoting the health of the aging brain. KEY WORDS: stress; hippocampal aging; glucocorticoid cascade hypothesis. @ 1999 Academic Press
\end{abstract}

\section{INTRODUCTION}

The hippocampus is a particularly vulnerable and sensitive region of the brain that is also very important for declarative and spatial learning and memory (36). Hippocampal neurons are vulnerable to seizures, strokes, and head trauma, as well as responding to stressful experiences $(27,92,130)$. At the same time they show remarkable plasticity, involving long-term synaptic potentiation and depression, dendritic remodeling, synaptic turnover, and neurogenesis in the case of the dentate gyrus (Fig 1) $(17,27,92)$.

The work of aus der Muhlen and Ockenfels (3) first drew attention to potentially toxic actions of adrenal steroids. The reported darkly stained neurons in the hippocampus of guinea pigs exposed to high levels of glucocorticoids, an observation that has been confirmed and extended to repeated stress

Address correspondence and reprint requests to Bruce S. McE wen at Laboratory of Neuroendocrinology, Rockefeller University, 1230 York Avenue, New York, NY 10021. Fax: 2123278634 E-mail:mcewen@rockvax.rockefeller.edu. 
Hippocampal function

- Spatial and declarative memory

- HPA regulation

- Processing of emotional information
Structural and Functional Plasticity

- Excitability, long-term potentiation

- Remodelling of dendrites

- Neurogenesis in dentate gyrus

- Synaptic remodelling

\section{Age-related changes}

- Neuronal loss (controversial)

- Calcium homeostasis - decreased

- Neurodegeneration markers - increased

- Dynorphin expression in dentate gyrus - increased
Experimental study of risk factors

- Metabolic instability (e.g., diabetes)

- Genetic vulnerability (transgenic mice)

- Cell culture models

- Insertion of genes (viral vectors)

FIG. 1. The hippocampal formation is a plastic and vulnerable region of the adult brain which is providing information about the ways in which the brain ages and therole of adrenal steroids and other modulators of neuronal function and survival. This figure shows the basicthree-cell neuroanatomical organization of the hippocampus and summarizes four aspects that are covered in the article.

in subsequent studies $(41,100)$, although there are still some doubts as to whether "dark neurons" may be artifacts of tissue trauma (18). In 1968, we discovered receptors for adrenal steroids in hippocampus (95), and it is now known that two types of adrenal steroid receptors exist in the hippocampus and other brain regions and mediate a variety of adrenal steroid effects on excitability, neurochemistry, and structure (27). Landfield (68) and then Sapolsky $(127,128)$ provided evidence for a role of adrenal steroids in neuronal aging in the hippocampus, leading to the formulation of the "glucocorticoid cascade hypothesis" (130). This hypothesis states that glucocorticoids participate in a feed-forward cascade of effects on the brain and body, in which progressive glucocorticoid-induced damage to the hippocampus promotes progressive el evation of adrenal steroids and dysregulation of the hypothalamopituitaryadrenal (HPA) axis (130).

Subsequent work has provided considerable support for the model for both brain and body aging and has extended our knowledge of the aging hippocampus from animal models to humans $(90,91,126,129)$, but at the same time the new information has reveal ed a number of complications and problems with the original formulation. First, finding neuronal death in the hippocampus during aging is technically very problematic, and recent information from ster eol ogical cell counting has down-played the importance of neuronal death as opposed to declining neuronal function and various forms of structural plasticity. Second, 
the role of the hippocampus in HPA regulation is more complex than originally believed, considering both its neuroanatomical connections to the hypothalamus and the nature of negative feedback regulation of the HPA axis. Third, glucocorticoids do not act al one on the hippocampus, and there is new information down-playing the relative importance of adrenal steroids as opposed to excitatory amino acids and other modulators, including neurotrophins and calcium ions. Fourth, new options exist in explaining the atrophy and functional impairment of the human hippocampus seen in various disorders, and these may involve protentially reversible forms of plasticity, as well as damaging effects of both glucocorticoids and excitatory amino acids. Finally, there are considerable individual differences in the aging process that complicate, but at the same time enrich, the study of age-related changes in the brain in populations of animals or human subjects; indeed, some investigators have turned this to good advantage in studying aging populations, and developmental studies of HPA axis function in relation to early experience have provided some basis for understanding how these differences may have arisen. Taken together, the new information has enriched our understanding of the aging process and, at the same time, provided opportunities for understanding risk and protective factors in the aging brain.

\section{OBTAINING AN ACCURATE DESCRIPTION OF THE AGING BRAIN AND BODY}

Chronological agealone is not sufficient to predict the state of the aging brain and body. The problem that individual differences pose for aging research is that individual animals or human subjects must be evaluated for cognitive and physical status, relative to other individuals of the same age, in order to understand the meaning of any single physiological, neuroanatomical, neurochemical, or molecular measure (89). For the hippocampus, as well as for the rest of the body, additional information is needed regarding both cognitive function and stress mediators (i.e., HPA and sympathetic nervous system reactivity), as well as measures of body function that are influenced by these mediators $(89,91)$. This is true not only for animal models (96) but also for studies on humans, for which longitudinal information about HPA activity and other measures of allostatic load (91) in aging subjects has been shown to predict cognitive decline and onset of cardiovascular disease $(78,79,131)$. Thus, the most meaningful studies have been done comparing cognitively impaired and unimpaired groups of aging individuals. We shall return to the topic of individual differences in a later section of this article.

\section{NEURON DEATH IS NOT INEVITABLE NOR THE ONLY CAUSE OF AGE-RE LATED IMPAIRMENT}

There has been a tendency to interpret the glucocorticoid cascade hypothesis as implying that hippocampal neuron death is an inevitable consequence of 
brain aging and that age-related impairments in cognitive function are solely related to such neuronal loss. This notion has given way to a more flexible view of brain aging, in which impairments in hippocampal functioning can be studied in terms of potentially reversible, as well as irreversible, changes in neuronal structure, neurochemistry, and function $(69,70,90,103)$.

The first challenge to the notion of neuronal loss is from a methodological problem in estimating neuron number in the brain. Because of the gradual time course of brain aging, even in rapidly-aging small animals like rats, observing neuronal death by counting dying neurons is futile because it would have to be such a slow process to account for the gradual changes in function. For that reason, studies of pyramidal neuron damage and the role and mechanism of action of glucocorticoids and excitatory amino acids have utilized kainic acid damage or transient ischemia models (126). In the aging brain, counting of neurons to determine the average decline in neuronal content of the hippocampus is also fraught with technical problems. The initial reports of the aging hippocampus identified a reduced density of pyramidal neurons in aging rats that also showed impairments of spatial and other memory tasks $(64,128)$. However, Mark West introduced a stereological counting procedure (73) and reported a failure to find reduced hippocampal neuron numbers in aging rats with memory impairment compared to aging rats without impairment (120). A similar negative finding was also published by Rapp and Gallagher in another study of aging cognitively impaired versus unimpaired rats (119).

Even while the issue of age-related neuronal loss is controversial, and by no means resolved, there is evidence that the aging hippocampus undergoes progressive changes with age in calcium homeostasis, the plasticity of response to glucocorticoids, and in the expression of markers related to neuroprotection and damage. The activity of L-type cal cium channels increases in hippocampal CA1 pyramidal neurons of aging rats and results in an increased afterhyperpolarization (70). In cultured embryonic hippocampal neurons that are maintained for 28 days, there is an increase in calcium channel activity and in after-hyperpolarization that is accompanied by decreased neuronal survival; blocking L-type calcium channels increased neuronal survival (116). It is interesting to notethat theincreased after-hyperpolarization is associated with an enhanced induction of long-term depression in CA1 pyramidal neurons and an impaired induction of long-term potentiation (105). Thus, insofar as LTP and LTD may be related to synaptic plasticity during learning (87), these age-related changes suggest a possible basis for cognitive impairment in aging rats (105).

Glucocorticoids enhance calcium channel activity and after-hyperpolarization $(60,70)$ and glucocorticoid receptor expression shows a progressive failure of negative feedback regulation in old versus young rats. In young rats, repeated stress causes a down-regulation of glucocorticoid receptor levels, thus decreasing glucocorticoid efficacy on various target genes, whereas this downregulation is lost with increasing age, thus preserving glucocorticoid actions (64). Thus, there is a natural mechanism in the young hippocampus for repeated stress to reduce the magnitude of the glucocorticoid feedback signal 
and thus reduce the impact of glucocorticoids on calcium channel activity, among other effects. This may be protective, insofar as increased calcium channel activity contributes to free radical generation and other processes that may damage neurons $(75,88)$. With the loss of stress-induced down-regulation of glucocorticoid receptors, ol der rats appear to lose this protective device and may be more vulnerable to increased levels of glucocorticoids which do appear to accompany aging, particularly in cognitively impaired rats (64).

Even if outright neuronal loss is not a major event in the aging hippocampus of cognitively impaired rats, there are indications that gene products associated with neurodegeneration and damage are differentially regulated in the aging-impaired brain compared to unimpaired aging rats and young rats, although the interpretation of the results is very complex (139). In aging, cognitively impaired rats, the levels of mRNA for the 695-amino-acid form of the $\beta$-amyloid precursor protein ( $\beta A P P)$ and for magnesium-dependent superoxide dismutase (Mg-SOD) were both elevated throughout the hippocampus compared with young rats; at the same time the levels of the $\beta A P P$ and Mg-SOD proteins were both depressed (139). Levels of mRNA for glial fibrillary acidic protein (GFAP), a marker of astrocytes which increases with damage, were el evated in the hippocampus of aging, cognitively impaired rats, although the level of the GFAP protein was not el evated (139). Since $\beta A P P$ gives rise to both a toxic $\beta$-amyloid protein and a protective secreted form, the reduced levels of $\beta$ APP expression in aging, cognitively impaired rats is difficult to interpret without a separate measurement of the two forms of the protein. On the other hand, lower Mg-SOD protein is consistent with a lower capacity for free radical scavenging and an increased risk of free radical-induced neural damage (22).

Another aspect of the aging hippocampus is alteration in glutamate release associated with an age-related increase in dynorphin content of the hippocampus (155). These changes are associated with impairments of spatial learning. Since dynorphin is present in the mossy fiber pathway as a cotransmitter with glutamate, the increased levels of this peptide may have an inhibitory autoregulatory function at the mossy fiber synapse in blocking the release of glutamate (155).

\section{THERE ARE MULTIPLE MECHANISMS OF PLASTICITY}

The hippocampus is not only a brain structure vulnerable to damage produced by seizures, ischemia, and head trauma, but its vulnerability is a sign that it is also a very plastic region of the brain. Adrenal steroids, which have a bad reputation as concerns their role in exacerbating these forms of damage (126), are also involved in three types of adaptive plasticity in the hippocampal formation. First, they reversibly and biphasically modulate the excitability of hippocampal neurons and influence the magnitude of long-term potentiation, as well as producing long-term depression $(27,63,109-112)$. These effects may be involved in bi phasic effects of adrenal secretion on excitability and cognitive 
function and memory during the diurnal rhythm and after stress $(8,24,31,34)$. In particular, acute nonpainful novelty stress inhibits primed-burst potentiation and memory $(32,33)$.

Second, adrenal steroids participate along with excitatory amino acids in regulating the neurogenesis of dentate gyrus granule neurons (17), in which acute stressful experiences can suppress the ongoing neurogenesis $(43,47)$. We bel ieve that these effects may be involved in fear-related learning and memory, because of the anatomical and functional connections between the dentate gyrus and the amygdala (57), a brain area important in the memory of aversive and fear-producing experiences (71).

Third, adrenal steroids participate along with excitatory amino acids in a reversible stress-induced atrophy, or remodeling, of dendrites in the CA 3 region of hippocampus of male rats (92) and tree shrews (85), a process that affects only the apical dendrites and results in cognitive impairment in the learning of spatial and short-term memory tasks (92). Although this type of plasticity does impair cognitive function at least temporarily, it may be beneficial to the brain in the long run if the remodeling of dendrites reduces the impact of excitatory amino acids and glucocorticoids in causing more permanent damage. This is an hypothesis that remains to be rigorously tested.

Besides what stress does to change the hippocampal structure, there are other forms of plasticity in the hippocampus, including reversible synaptogenesis that is regulated by ovarian steroids and excitatory amino acids via NMDA receptors in female rats and occurs in the CA1 region $(44,150,152)$ and a reversible atrophy of dendrites of CA3 neurons during hibernation in ground squirrels and hamsters $(114,115)$. The estrogen-regulated CA1 synaptic plasticity is a rapid event, occurring during the female rats' 5-day estrous cycle, with the synapses taking several days to be induced under the influence of estrogens and endogenous glutamic acid and then disappearing within $12 \mathrm{~h}$ under the influence of the proestrus surge of progesterone (94).

In contrast, the CA3 atrophy found in rats and noted in the preceding paragraph is a relatively slow process, normally taking at least 3 weeks to develop under daily stress and a week or so to disappear. However, dendritic atrophy in hibernating ground squirrels and hamsters develops as fast as the hibernating state and can be reversed rapidly within several hours [(114,115); A.-M. Magarinos, B.S. McE wen, and P. Pevet, unpublished]. Although anatomically similar to the stress-induced atrophy in rats and tree shrews, it is not yet clear if this process involves the same mechanisms; however, if this is the case, the question becomes what factors make the atrophy process so rapid in hibernation and so slow in the case of repeated stress.

\section{GLUCOCORTICOIDS DO NOT WORK ALONE}

Many of the above-mentioned hormone effects on morphology and function of the hippocampus do not occur alone but rather in the context of ongoing neuronal activity. In particular, excitatory amino acids and NMDA receptors 
play an important role in the adaptive functional and structural changes produced in the hippocampal formation by steroid hormones. This includes not only the estradiol-induced synaptogenesis but also the effects of adrenal steroids to produce atrophy of CA3 pyramidal neurons (92), as well as the actions of adrenal steroids to contain dentate gyrus neurogenesis (17). Blocking NMDA receptors blocks atrophy as well as estrogen-induces synaptogenesis $(83,151)$, and NMDA receptors are induced by estrogens on CA1 neurons $(44,146)$ and by glucocorticoids throughout the hippocampus (148). At the same time, excitatory amino acids and NMDA receptors are involved in the destructive actions of stress and trauma on the hippocampus (126), and one of the challenges for future research is to understand what triggers the transition from adaptive plasticity to permanent damage.

With regard to the remodelling of dendrites in the CA3 region, the role of glucocorticoids is complex. Glucocorticoid treatment, using both injections or drinking water application, causes dendritic remodeling/atrophy, and stressinduced atrophy of these same dendrites is blocked by treatment with an adrenal steroid synthesis blocker, cyanoketone [see (92)], indicating a role of endogenous glucocorticoids in stress-induced dendritic atrophy. There appear to be several ways in which glucocorticoids affect the excitatory amino acid system and thus regulate this form of plasticity. First, adrenal steroids modulate expression of NMDA receptors in hippocampus $(9,147)$, with chronic glucocorticoid exposure leading to increased expression of NMDA receptor binding and both NR2A and NR2B subunit mRNA levels (148). Second, there are glucocorticoid effects on the expression of mRNA levels for specific subunits of GABAa receptors in CA3 and the dentate gyrus; both low and high levels of CORT have different effects on GABAa receptor subunit mRNA levels and receptor binding [(107); M. Orchinik, N. Weiland, and B.S. McE wen, unpublished], suggesting that corticosterone may alter the excitability of hippocampal neurons through regulation of GABAa receptor expression. However, it remains to be seen if the corticosteroid effects on neuronal morphology involve changes in the number or pharmacological properties of GABAa receptors. Third, adrenal steroids regulate the rel ease of glutamate, since adrenal ectomy markedly reduces the magnitude of the EAA rel ease evoked by restraint stress $(76,101)$. Mossy fiber terminals in the stratum lucidum contain presynaptic kainate receptors that positively regulate glutamate rel ease (23); these presynaptic kainate receptors are decreased in density by ADX and restored to normal by corticoster one replacement (145). Mor eover, repeated stress causes a reorganization of synaptic vesicles within mossy fiber terminals, as reported recently using electron microscopy (86). Whereas mossy fiber terminals (MFT) from control rats were packed with small, clear synaptic vesicles, terminals from rats receiving 21 days of restraint stress (but not after a single stress session) showed a marked rearrangement of vesicles with more densely packed clusters localized in the vicinity of active synaptic zones. Moreover, compared with controls, restraint stress increased the area of the mossy fiber terminal occupied by mitochondrial profiles, which implies a greater, localized energy generating capacity. 


\section{THE HIPPOCAMPUS AND HPA REGULATION}

The hippocampus is involved in the regulation of HPA activity (58), although the nature of this regulation is more complex than originally suspected. In general, the hippocampus has an inhibitory role (58), whereas the amygdala has a generally facilitative role $(14,118,124)$. Hippocampal lesions produced elevated cortisol secretion under a variety of stressful and nonstressful conditions (58), although the results reported in the literature are not entirely consistent [e.g., see $(16,58)]$. Glucocorticoid implants into the hippocampus affect HPA activity in ways that are consistent with a feedback role of the hippocampus in HPA regulation [see (58)]. However, lesion and steroid implant experiments also reveal an equally important role for the medial prefrontal cortex in HPA regulation (35). The anatomical links from the hippocampus and medial prefrontal cortex to the hypothalamus are postulated to be via the bed nucleus of the stria terminalis and preoptic area, with an output from these structures to the paraventricular nucleus via inhibitory GABAergic projections (53).

Considerable data have accumulated showing that elevated HPA activity is correlated with reduced levels of Typel or Typell receptors in the hippocampus (58) or prefrontal cortex (53). In general, hippocampal Type I receptors are associated with the maintenance of basal ACTH and glucocorticoid levels $(15,27,136,137)$; forebrain Typell receptors are also associated with the containment of ACTH secretion $(15,137)$. It is uncl ear whether correlations of hippocampal Type I and Type II receptor levels with HPA activity indicate a feedback action of adrenal steroids on the hippocampus or a priming role for glucocorticoids to make the HPA axis optimally reactive to turning on and off a stress response by neural signals, as suggested by recent studies by Dallman and colleagues (2). It is this last aspect of HPA regulation that is the most intriguing, namely, that the role of the hippocampus may be as an adrenal steroidprimed modulator of neural activity that is involved in regulating hypothalamic output of CRF and vasopressin. In other words, "shutoff" of the HPA stress response may be due to steroid-modulated neural input, e.g., increasing inhibitory input to the PVN (53), rather than due exclusively to rapid and delayed steroid feedback at the level of the PVN neuron or pituitary corticotroph.

Many but not all studies show increased levels of glucocorticoids in aging rats and humans $(89,125,132,144,149)$. The reasons for these differences are likely to relate to individual differences in brain aging and in the differences in the distribution of aging, impaired individuals in populations of animals and human subjects (89). Particularly useful have been studies of basal cortisol levels and cognitive deficits in human aging $(78,79)$. Aged subjects followed over a 4-year period, who showed a significant increase in cortisol levels over the 4 years and had high basal cortisol levels in year 4, showed deficits on tasks measuring explicit memory as well as sel ective attention compared to subjects with either decreasing cortisol levels over 4 years or subjects with increasing basal cortisol but moderate current cortisol levels (78). They also showed a 
hippocampus that was $14 \%$ smaller than those of age-matched controls who did not show progressive cortisol increases and were not cognitively impaired (79).

Elevated and disregulated HPA activity is also seen in depressive illness $(46,154)$, but the reasons for this el evation are not entirely clear. Disregulation of the HPA axis associated with major depression is revealed by the dexamethasone suppression test (DST) $(19,20)$. Although the DST is most likely working at the pituitary level (99), the underlying disregulation is undoubtedly of CNS origin and reflects increased drive upon the CRH and AVP systems of the hypothalamus (45) and constitutes a form of endogenously driven stress. A lessening of the adrenal steroid feedback effects on the hippocampus might bea contributing factor to el evated HPA activity in depression, and recent studies of Barden and co-workers with a transgenic mouse strain $(7,56)$ have suggested that decreased forebrain Type II receptor expression might be a contributing factor to depression and a potential target of antidepressant therapy $(56,102)$. It is not clear, however, how much hippocampal Type II receptor expression, as opposed to receptor expression in other brain regions, is a key factor.

There is another linkage of the hippocampus with el evated cortisol levels. Recent studies using MRI imaging have indicated that elevated cortisol levels are associated with some shrinkage of the hippocampal formation and mild cognitive impairment $(4,79,133,138)$. This will be discussed more extensively bel ow. Such findings raise the "chicken-and-egg" question, whether hippocampal atrophy is both a cause and a result of the elevated glucocorticoids and whether the cognitive impairment accompanying these conditions is due to the hippocampal atrophy or to el evated glucocorticoids affecting neuronal excitability or both. The acute effects of glucocorticoids on memory are recognized and have been reviewed recently (81). In general, an acute el evation of glucocorticoids by injection causes acute cognitive impairment of declarative memory in human subjects [see (66); S. L upien, personal communication]. Nevertheless, in spite of one positive report (66), it is not as certain whether acute stressinduced elevations of corticosteroids can do the same [see (80)]. This may be a question of the magnitude of the stress-induced cortisol rise, since a bolus injection of cortisol not only impairs declarative memory but also suppresses temporal lobe uptake of glucose (26).

\section{THE PROBLEMS AND OPPORTUNITIES OF STUDYING INDIVIDUAL DIFFERENCES}

We now return to the question of individual differences in brain and body aging and discuss the possible determinants of these individual differences. There are two major factors: genetic constitution and environmental influences, and we know that gene expression is regulated by environmental factors and that hormones play a major role in the regulation of gene expression. Therefore, the discussion of the determinants of individual differences can be framed, at least in part, as a question of how experience influences brain development and adult function. 
The vulnerability of many systems of the body to stress is influenced by experiences early in life. In animal models, unpredictable prenatal stress causes increased emotionality and increased reactivity of the HPA axis and autonomic nervous system and these effects last throughout the lifespan. Postnatal handling in rats, a mild stress involving brief daily separation from the mother, counteracts the effects of prenatal stress and results in reduced emotionality and reduced reactivity of the HPA axis and autonomic nervous system $(1,54,72)$. The vulnerability of the hippocampus to age-related loss of function parallels these effects-prenatal stress increasing and postnatal handling decreasing the rate of brain aging $(28,96)$. Concurrently, age-related decline of gonadal function reduces the beneficial and protective actions of these hormones on brain function. At the same time, age-related increases in adrenal steroid activity promote age-related changes in brain cells that can culminate in neuronal damage or cell death. Lifel ong patterns of adrenocortical function, determined by early experience, contribute to rates of brain aging, at least in experimental animals.

Unpredictable or uncontrollable stressful experiences of a pregnant rat increase emotionality and stress hormone reactivity in offspring that last for the lifetime of the individual, whereas the gentle and repeated stimulation of newborn rat pups known as postnatal handling produces reductions in emotionality and stress hormone reactivity that also last a lifetime $(1,29,38$, $72,96,142$ ). These effects appear to involve mediation by both the mother's behavior and by adrenal and thyroid hormone actions. More is known about the mechanism of neonatal handling. Handling involves separating the pups from the mother for 10 min per day for the first 2 weeks of neonatal life, and the licking of the pup by the mother appears to be an important determinant of the postnatal handling effect (74). At the same time, increasing corticosterone levels in the mother's milk mimic some of the effects of neonatal handling (21), and thyroid hormone el evations have been suggested as a possible mediator of the neonatal handling effect, particularly regarding the el evated expression of glucocorticoid receptors in the hippocampus (97).

Studies in which both prenatal stress and postnatal handling were compared indicate that these two procedures have opposite effects on food intake, body weight, and anxiety, as well as HPA activity $(142,143)$. However, the two processes interact, in that prenatal stress effects on HPA activity and emotionality are reversed by early postnatal "adoption" or cross-fostering of pups to new mothers $(6,82)$, which is most likely a form of postnatal handling involving intense licking of the pup by the mother (74). Prenatal stress during the last week of gestation in rats increases reactivity of the HPA axis and reduces expression of the Typel adrenal steroid receptor in hippocampus, which help to contain basal levels of HPA activity $(52,143)$. Prenatal stress also increases anxiety in an open field test and decreases basal food intake and body weight $(142,143)$. It is important to note that some of the these prenatal stress effects may involve a mediation by adrenal steroids (5). Taken together with the fact that postnatal handling effects may also be mimicked by adrenal steroids (21), the specific effects of adrenal steroids on the neural devel opment of emotional- 
ity and HPA reactivity may change qualitatively as the nervous system matures.

For prenatal stress and postnatal handling, once the emotionality and the reactivity of the adrenocortical system are established by events early in life, it is the subsequent actions of the HPA axis in adult life that play a major role in determining the rate of brain and body aging. Increased HPA activity is associated with increased brain aging, whereas the opposite is true of animals with reduced HPA reactivity to novel situations. Rats with increased HPA reactivity show early decline of cognitive functions associated with the hippocampus (28) as well as increased propensity to self-administer drugs such as amphetamine and cocaine $(30,113)$. In contrast, rats with a lower HPA reactivity as a result of neonatal handling have a slower rate of cognitive aging and a reduced loss of hippocampal function $(21,98)$.

Is therea human counterpart to the story of individual differences in rat HPA activity and hippocampal aging? We simply cannot say at this moment, but individual differences in human brain aging that are correlated with cortisol levels have been recognized in otherwise healthy individuals that are followed over a number of years $(78,79,131)$. In the most extensive investigation, healthy elderly subjects were followed over a 4-year period, and those who showed a significant and progressive increase in cortisol levels during yearly exams over the 4 years and had high basal cortisol levels in year 4 showed deficits on tasks measuring explicit memory as well as selective attention, compared to subjects with either decreasing cortisol levels over 4 years or subjects with increasing basal cortisol but moderate current cortisol levels (78). They also showed a hippocampus that was $14 \%$ smaller than those of agematched controls who did not show progressive cortisol increases and were not cognitively impaired (79). In the other study of successful aging, increases in overnight urinary cortisol secretion from 1988 to 1991 predicted declines in cognitive function in women, while the effect was not significant in men (131). This finding, which is being extended in a new data collection (Dr. Teresa Seeman, UCLA, personal communication), brings up the topic of sex differences.

\section{IMPORTANCE OF SEX DIFFERENCES AND SEX HORMONES}

One factor that may contribute to individual differences in age is gender and the effects of sex hormones and the process of sexual differentiation. Sex differences in brain structures and mechanisms occur in other brain regions besides hypothalamus, such as hippocampus, and they appear to be involved in aspects of cognitive function and other processes that go beyond the reproductive process itself, such as the higher incidence of depression in women and of substance abuse in men (122). There are also sex differences in the severity of brain damage resulting from transient ischemia (49) and sex differences in the response of the brain to lesions (104) and to severe, chronic stress $(100,141)$. A recent study has shown that the stress-induced atrophy of apical dendrites of 
CA3 pyramidal neurons occurs in male rats but not in female rats (42). What is not yet clear in this case is whether this atrophy, which is reversible (see above), increases or decreases the vulnerability of the male and female brain to permanent damage.

Estrogens appear to have protective effects on the brain in relation to aging, as well as acute effects on verbal memory and other cognitive functions linked to the hippocampus. In animal experiments, it has been difficult to detect cyclicity of performance in spatial tasks, with no effect reported (11), or differences reported in motivational or attentional parameters (13), or an impairment reported in performance on proestrus (40). This lack of agreement and paucity of effects may be a reflection of the relative insensitivity of the measures used to detect behaviors that female rats actually use in their natural environments at the time of mating. However, some success has resulted from studying longer term effects of ovariectomy and estrogen replacement on hippocampal-dependent learning and memory, for which there are unfortunately no good morphological or physiological correlates at the present time. Three types of effects have been reported in animal models. First, estrogen treatment of ovariectomized female rats has been reported to improve acquisition on a radial maze task as well as in a reinforced T-maze alternation task $(25,37)$. Second, sustained estrogen treatment is reported to improve performance in a working memory task (106) as well as in the radial arm maze $(25,77)$. Third, estrogen treatment is reported to promote a shift in the strategy that female rats use to solve an appetitive two-choice discrimination, with $E$ treatment increasing the probability of using a response strategy as opposed to a spatial strategy (67). Fourth, aging female rats that have low plasma estradiol levels in the "estropause" are reported to perform significantly worse in a Morris water maze than female rats with high estradiol levels (61).

The effects of estrogen replacement in rats are reminiscent of the effects of estrogen treatment in women whose ovarian function has been eliminated by surgical menopause or by an $\mathrm{GnRH}$ antagonist used to shrink the size of fibroids prior to surgery $(123,134,135)$. In general, these effects are seen within a number of weeks and are reversible. Another aspect of estrogen action in the aging brain is that estrogen treatment of postmenopausal women appears to have a protective effect on the brain reAlzheimer's disease $(12,50,51,62,108,140)$. It is likely that these protective actions involve a number of other actions of estrogens besides inducing synapses. These include suppression of the production of the toxic form of $\beta$-amyloid protein $(59,153)$ and inhibition of free radical-induced toxicity $(10,48)$. It should also be noted that estrogens affect many regions of the brain, including the basal forebrain cholinergic systems, the serotonergic system, the dopaminergic system, and the noradrenergic system [for review, see $(93,94)]$, so that the hippocampus is not the only target that may be involved in these cognitive changes.

Finally, it is important to note that virtually nothing is known about protective effects toward Alzheimer's disease in men, either by estrogens or by testosterone; this is an area deserving of investigation. 


\section{ARE AGE-RELATED ME MORY IMPAIR MENTS TREATABLE?}

It is evident that adrenal steroids affect the structure and function of the hippocampus in a variety of ways, and we have also seen that, in human subjects, there is evidence for both cognitive impairment and hippocampal atrophy associated with altered levels of adrenal steroids and traumatic stress, as in Cushing's disease, recurrent depressive illness, posttraumatic stress disorder, as well as individual differences in aging (90). Besides permanent damage and loss of neurons, what are the possible mechanisms for the atrophy and are they treatable? Permanent loss of neurons is one possibility, but this article has summarized various alternatives, including atrophy of neuronal processes and a decreased number of dentate gyrus granule neurons. F or these processes, we have also seen that adrenal steroids do not act al one. In the case of dendritic atrophy in hippocampus, both excitatory amino acids and serotonin release, possibly facilitated by circulating glucocorticoids, play a key role. In fact, the final common path for CA3 dendritic atrophy in rats treated with either corticosterone or by restraint stress involves processes that are blocked by blocking glutamate release or actions using phenytoin or an NMDA antagonist, respectively, or by facilitating serotonin reuptake using tianeptine. The efficacy of these agents raises the attractive possibility of treating individualsperhaps the depressed elderly — with agents such as phenytoin or tianeptineas a means of improving cognitive function (90). If such studies are carried out, it will be important to determinethe degreeto which hippocampal volume may be increased by such treatments and whether long-term treatment protects these same individuals from dementia.

\section{HOW TO DEFINE PROTECTIVE FACTORS IN THE BRAIN}

The fact that the brain is normally resilient in the face of acute and repeated stress indicates that there are protective factors that promote resilience of brain cells in the face of stressful challenges. There are at least four approaches to identify protective factors. The first is to manipulate genes that are likely to provide protection, such as the neurotrophins or superoxide dismutase; mice with deficiencies in these genes should be more vulnerable to stress-induced damage of hippocampal structure and function, and studies are under way to test the validity of this strategy. The second approach is to manipulate metabolic factors, e.g., by making rats diabetic or by stressing animals that have genetic risk for either Type I or Type II diabetes. Some initial results indicate that diabetes may accel erate stress-induced dendritic atrophy in the hippocampus and promote stress-induced neuronal damage $(84,121)$. A third approach is to use hippocampal cell culture models and study the interaction of androgens, estrogens, glucocorticoids, and excitatory amino acids in producing excitotoxic damage $(48,116,117,126)$. As noted above, the vulnerability to excitotoxicity in hippocampal neurons has been related to increased calcium channel activity that develops with increasing age in culture (116). The cell culture approach 
has been extended recently to demonstrate the protective effects of another steroid that declines with age in humans, namely, dehydroepiandrosterone (DHEA), toward NMDA-induced neurotoxicity (65). A fourth strategy is to use targeted delivery of genetic material in viral vectors in order to overcome the restrictions of energy supply in the face of excitotoxic challenge using local enhancement of glucose transporter activity (55).

\section{CONCLUSIONS}

The glucocorticoid cascade hypothesis of hippocampal aging, published in 1986 (130), has served extremely well to promote research into the factors that cause individual differences in rates of brain aging. This research, together with advances in many other aspects of neuroscience in the past 12 years, has led to a far more sophisticated view of the interactions between genes, early development, and environmental influences, as well as strengthening the methods that are used to study the aging brain. It has also led to a greater appreciation of events at the cellular and molecular level which protect neurons, as well as pathways for neuronal damageand destruction. While documenting the ultimate vulnerability of the brain to stressful challenges and to the aging process, the net result of this research is an optimistic view of the resilience of the brain and new hope to develop treatment strategies to maintain this resilience in the aging brain.

\section{ACKNOWLEDGMENTS}

Research in the author's laboratory on some of the topics discussed in this article is supported by NIH Grants NS07080 and MH41256 and by the Health Foundation (New York), Servier (France), and UCB (Belgium).

\section{REFERENCES}

1. Ader R. Effects of early experiences on emotional and physiological reactivity in the rat. J Comp Physiol Psychol 1968; 66: 264-268.

2. Akana SF, J acobson L, Cascio CS, Shinsako J, Dallman MF. Constant corticosterone replacement normalizes basal adrenocorticotropin (ACTH) but permits sustained ACTH hypersecretion after stress in adrenal ectomized rats. Endocrinol ogy 1988; 122: 1337.

3. aus der Muhlen $\mathrm{K}$, Ockenfels $\mathrm{H}$. Morphologische veranderungen im diencephalon und telencephalon: Storungen des regelkreises adenohypophysenebennierenrinde. Z Zellforsch Mikrosck Anat 1969; 93: 126-141.

4. Axelson D, Doraiswamy A, McDonald W, Boyko O, Typler L, Patterson L, Nemeroff CB, Ellinwood EH, Krishan KRR. Hypercortisolemia and hippocampal changes in depression. Psychiatr Res 1993; 47: 163-173.

5. Barbazanges A, Piazza VP, Le Moal M, Maccari S. Maternal glucocorticoid secretion mediates long-term effects of prenatal stress. J Neurosci 1996; 15: 3943-3949. 
6. Barbazanges A, Vallee M, Mayo W, Day J, Simon H, Le Moal M, Maccari S. Early and later adoptions have different long-term effects on male rat offspring. J Neurosci 1996; 16: 7783-7790.

7. Barden N, Stec ISM, Montkowski A, Holsboer F, Reul JMHM. Endocrine profile and neuroendocrine challenge tests in transgenic mice expressing antisense RNA against the glucocorticoid receptor. Neuroendocrinol ogy 1997; 66: 212-220.

8. Barnes C, McNaughton B, Goddard G, Douglas R, Adamec R. Circadian rhythm of synaptic excitability in rat and monkey central nervous system. Science 1977; 197: 91-92.

9. Bartanusz V, Aubry J M, Pagliusi S, J ezova D, Baffi J , Kiss J Z. Stress-induced changes in messenger RNA levels of $\mathrm{N}$-methyl-D-aspartate and Ampa receptor subunits in selected regions of the rat hippocampus and hypothalamus. Neuroscience 1995; 66: 247-252.

10. Behl C, Skutella T, Lezoual c'h F, Post A, Widmann M, Newton CJ , Holsboer F. Neuroprotection against oxidative stress by estrogens: Structure-activity relationship. Mol Pharm 1997; 51: 535-541.

11. Berry B, McMahan R, Gallagher M. The effects of estrogen on performance of a hippocampaldependent task. Soc Neurosci Abstr 1996; 22: No. 547.8-P1386. [abstract].

12. Birge SJ. The role of estrogen deficiency in the aging central nervous system. In: Lobo RA, Ed. Treatment of the Postmenopausal Woman: Basic and Clinical Aspects. New York: Raven Press, 1994: 153- 157.

13. Blasberg ME, Stackman RW, Langan CJ , Clark AS. Dynamics of working memory across the estrous cycle. Soc Neurosci Abstr 1996; 22: No. 547.5-P1386. [abstract].

14. Bohus B, Kool haas J M, Luiten PGM, Korte SM, Roozendaal B, Wiersma A. The neurobiology of the central nucleus of the amygdala in relation to neuroendocrine and autonomic outflow. Prog Brain Res 1996; 107: 447-460.

15. Bradbury MJ , Akana SF, Dallman MF. Roles of Type I and II corticosteroid receptors in regulation of basal activity in the hypthalamo-pituitary-adrenal axis during the diurnal trough and peak: Evidence for a nonadditive effect of combined receptor occupation. Endocrinology 1994; 134: 1286-1296.

16. Bradbury MJ, Strack AM, Dallman MF. Lesions of the hippocampal efferent pathway (fimbria-fornix) do not alter sensitivity of adrenocorticotropin to feedback inhibition by corticosterone in rats. Neuroendocrinol ogy 1993; 58: 396- 407.

17. Cameron HA, Gould E. The control of neuronal birth and survival. In: Shaw CA, Ed. Receptor Dynamics in Neural Development. New York: CRC Press, 1996: 141-157.

18. Cammermeyer J. Is the solitary dark neuron a manifestation of postmortem trauma to the brain inadequately fixed by perfusion? Histochemistry 1978; 56: 97-115.

19. Carroll B, Curtis G, Mendels J . Neuroendocrine regulation in depression. Arch Gen Psychol 1976; 33: 1051-1058.

20. Carroll BJ , Martin FIR, Davies B. Resistance to suppression by dexamethasone of plasma 11-O.H.C.S. levels in severe depressive illness. Br Med J 1968; 3: 285-287.

21. Catalani A, Marinelli M, Scaccianoce S, Nicolai R, Muscolo LAA, Porcu A, Koranyi L, Piazza PV, Angelucci L. Progeny of mothers drinking corticosterone during lactation has lower stress-induced corticosterone secretion and better cognitive performance. Brain Res 1993; 624: 209-215.

22. Chan PH. Role of oxidants in ischemic brain damage. Stroke 1996; 27: 1124-1129.

23. Chittajallu R, Vignes M, Dev KK, Barnes J M, Collingridge GL, Henley J M. Regulation of glutamate release by presynaptic kainate receptors in the hippocampus. Nature 1996; 379: 78-81.

24. Dana RC, Martinez J L. Effect of adrenalectomy on the circadian rhythm of LTP. Brain Res 1984; 308: 392-395.

25. Daniel J M, Fader AJ , Spencer A, Wee BEF. Effects of estrogen and environment on radial maze acquisition. Soc Neurosci Abstr 1996; 22: N o. 547.7-P1386. [abstract]. 
26. DeKloet ER, Vreugdenhil E, Oitzl MS, J oels M. Brain corticosteroid receptor balance in health and disease. Endocr Rev 1998; 19: 269-301.

27. Deleon MJ , McRae T, Rusinek H, Convit A, De Santi S, Tarshish C, Golomb J , Volkow N, Daisley K, Orentreich N, McE wen BS. Cortisol reduces hippocampal glucose metabolism in normal elderly, but not in Alzheimer's disease. J Clin Endocrinol Metab 1997; 82: 32513259.

28. Dellu F, Mayo W, Vallee M, LeMoal M, Simon H. Reactivity to novelty during youth as a predictive factor of cognitive impairment in the elderly: A longitudinal study in rats. Brain Res 1994; 653: 51-56.

29. Denenberg VH, Haltmeyer GC. Test of the monotonicity hypothesis concerning infantile stimulation and emotional reactivity. J Comp Physiol Psychol 1967; 63: 394-396.

30. Deroche V, Piazza PV, LeM oal M, Simon H. Individual differences in the psychomotor effects of morphine are predicted by reactivity to novelty and influenced by corticosterone secretion. Brain Res 1993; 623: 341-344.

31. Diamond DM, Bennett MC, Fleshner M, Rose GM. I nverted-U relationship between thelevel of peripheral corticosterone and the magnitude of hippocampal primed burst potentiation. Hippocampus 1992; 2: 421-430.

32. Diamond DM, Fleshner M, Ingersoll N, Rose GM. Psychological stress impairs spatial working memory: Relevance to electrophysiological studies of hippocampal function. Behav Neurosci 1996; 110: 661-672.

33. Diamond DM, Fleshner M, Rose GM. Psychological stress repeatedly blocks hippocampal primed burst potentiation in behaving rats. Behav Brain Res 1994; 62: 1-9.

34. Diamond DM, Fleshner M, Rose GM. Psychological stress impairs spatial working memory. Behav Neurosci 1996; 110: 661-672.

35. Diorio D, Viau V, Meaney MJ . The role of the medial prefrontal cortex (cingulategyrus) in the regulation of hypothalamic-pituitary-adrenal responses to stress. J Neurosci 1993; 13: 3839-3847.

36. Eichenbaum H. How does the brain organize memories? Science 1997; 277: 330-332.

37. Fader AJ , Hendricson AW, Dohanich GP. Effects of estrogen treatment on T-mazealternation in female and male rats. Soc Neurosci Abstr 1996; 22: No. 547.6-P1386. [abstract].

38. Fride E, Dan Y, Feldon J, Halevy G, Weinstock M. Effects of prenatal stress on vulnerability to stress and prepubertal and adult rats. Physiol Behav 1986; 37: 681-687.

39. Deleted in proof.

40. Frye CA. Estrus-associated decrements in a water maze task are limited to acquisition. Physiol Behav 1995; 57: 5-14.

41. Fuchs E, Uno H, Flugge G. Chronic psychosocial stress induces morphological alterations in hippocampal pyramidal neurons of the tree shrew. Brain Res 1995; 673: 275-282.

42. Galea LAM, McE wen BS, Tanapat P, Deak T, Spencer RL, Dhabhar FS. Sex differences in dendritic atrophy of CA3 pyramidal neurons in response to chronic restraint stress. Neuroscience 1997; 81: 689-697.

43. Galea LAM, Tanapat P, Gould E. Exposure to predator odor suppresses cell proliferation in the dentate gyrus of adult rats via a cholinergic mechanism. Soc Neurosci Abstr 1996; 22: No. 474.8-1196.

44. Gazzaley AH, Weiland NG, McE wen BS, Morrison J H. Differential regulation of NMDAR1 mRNA and protein by estradiol in the rat hippocampus. J Neurosci 1996; 16: 6830-6838.

45. Gold PW, Licinio J, Wong ML, Chrousos GP. Corticotropin releasing hormone in the pathophysiology of melancholic and atypical depression and in the mechanism of action of antidepressant drugs. Ann N Y Acad Sci 1995; 771: 716-729.

46. Gold PW, Wong ML, Chrousos GP, Licinio J . Stress system abnormalities in mel ancholic and atypical depression: Molecular, pathophysiological, and therapeuticimplications. Mol Psychiatr 1996; 1: 257-264. 
47. Gould E, McE wen BS, Tanapat P, Galea LAM, Fuchs E. Neurogenesis in the dentate gyrus of the adult tree shrew is regulated by psychosocial stress and NMDA receptor activation. J Neurosci 1997; 17: 2492-2498.

48. Grindley KE, Green PS, Simpkins J W. Low concentrations of estradiol reduce $\beta$-amyloid (25-35) induced toxicity, lipid peroxidation and glucose utilization in human SK-N-SH neuroblastoma cells. Brain Res 1997; 778: 158-165.

49. Hall ED, Pazara KE, Linseman KL. Sex differences in postischemic neuronal necrosis in gerbils. J Cereb Blood Flow Metab 1991; 11: 292-298.

50. Henderson VW, Paganini-Hill A, Emanuel CK, Dunn ME, Buckwalter J G. Estrogen replacement therapy in older women: Comparisons between Alzheimer's Disease cases and nondemented control subjects. Arch Neurol 1994; 51: 896-900.

51. Henderson VW, Watt L, Buckwalter J G. Cognitive skills associated with estrogen replacement in women with Alzheimer's Disease. Psychoneuroendocrinol ogy 1996; 12: 421-430.

52. Henry C, Kabbaj M, Simon H, LeMoal M, Maccari S. Prenatal stress increases the hypothalamo-pituitary-adrenal axis response in young and adult rats. J Neuroendocrinol 1994; 6: 341-345.

53. Herman JP, Cullinan WE. Neurocircuitry of stress: Central control of the hyopthalamopituitary-adrenocortical axis. Trends Neurosci 1997; 20: 78-84.

54. Hess J L, Denenberg VH, Zarrow MX, Pfeifer WD. Modification of the corticosteroneresponse curve as a function of handling in infancy. Physiol Behav 1968; 4: 109-111.

55. Ho DY, Saydam TC, Fink SL, Lawrence MS, Sapolsky RM. Defective herpes simplex virus vectors expressing the rat brain glucose transporter protect cultured neurons from necrotic insults. J Neurochem 1995; 65: 842-850.

56. Holsboer F, Barden N. Antidepressants and hyptohalamic-pituitary-adrenocortical regulation. Endocr Rev 1996; 17: 187-205.

57. I kegaya $Y$, Saito H, Abe K. The basomedial and basolateral amygdaloid nuclei contribute to the induction of long-term potentiation in the dentate gyrus in vivo. Eur J Neurosci 1997; 8: 1833-1839.

58. J acobson L, Sapolsky R. The role of the hippocampus in feedback regulation of the hypothalamic-pituitary-adrenocortical axis. Endocr Rev 1991; 12: 118-134.

59. J affe AB, Toran-Allerand CD, Greengard P, Gandy SE. Estrogen regulates metabolism of Alzheimer amyloid $\beta$ precursor protein. J Biol Chem 1994; 269: 13065-13068.

60. J oels M. Steroid hormones and excitability in the mammalian brain. Front Neuroendocrinol 1997; 18: 2-48.

61. J uraska J M, Warren SG. Spatial memory decline in aged, non-cycling female rats varies with the phase of estropause. Soc Neurosci Abstr 1996; 22: No. 547.12-P1387. [abstract].

62. Kawas C, Resnick S, Morrison A, Brookmeyer R, Corrada M, Zonderman A, Bacal C, Lingle DD, Metter E. A prospective study of estrogen replacement therapy and the risk of developing Alzheimer's disease: The Baltimore Longitudinal Study of Aging. Neurology 1997; 48: 1517-1521.

63. Kerr DS, Huggett AM, Abraham WC. Modulation of hippocampal long-term potentiation and long-term depression by corticosteroid receptor activation. Psychobiology 1994; 22: 123-133.

64. Kerr S, Campbell L, Applegate M, Brodish A, Landfield P. Chronic stress-induced acceleration of electrophysiologic and morphometric biomarkers of hippocampal aging. J Neurosci 1991; 11: 1316-1324.

65. Kimonides VG, Khatibi NH, Sofroniew MV, Herbert J . Dehydroepiandrosterone (DHEA) and DHEA-sulfate (DHEAS) protect hippocampal neurons against excitatory amino acidinduced neurotoxicity. Proc Natl Acad Sci USA 1998; 95: 1852-1857.

66. Kirschbaum C, Wolf OT, May M, Wippich W, Hellhammer DH. Stress- and treatmentinduced elevations of cortisol levels associated with impaired verbal and spatial declarative memory in healthy adults. LifeSci 1996; 58: 1475-1483. 
67. Korol DL, Couper J M, Mcl ntyreCK, Gold PE. Strategies for learning across the estrous cycle in female rats. Soc Neurosci Abstr 1996; 22: No. 547.4-P1386. [abstract].

68. Landfield P, Waymire J, Lynch G. Hippocampal aging and adrenocorticoids: Quantitative correlation. Science 1978; 202: 1098-1101.

69. Landfield PW. Modulation of brain aging correlates by long-term alterations of adrenal steroids and neurally-active peptides. Prog Brain Res 1987; 72: 279-300.

70. Landfield PW, Eldridge J C. Evolving aspects of the glucocorticoid hypothesis of brain aging: Hormonal modulation of neuronal calcium homeostasis. Neurobiol Aging 1994; 15: 579-588.

71. LeDoux J E. In search of an emotional system in the brain: leaping from fear to emotion and consciousness. In: Gazzaniga M, Ed. The Cognitive Neurosciences. Cambridge: MIT Press, 1995: 1049-1061.

72. Levine S, Haltmeyer GC, Karas GG, Denenberg VH. Physiological and behavioral effects of infantilestimulation. Physiol Behav 1967; 2: 55-59.

73. Lindvall-Axelsson $M$, Hedner $P$, Owman C. Corticosteroid action on choroid plexus: Reduction in $\mathrm{Na}^{+}-\mathrm{K}^{+}$-ATPase activity, choline transport capacity, and rate of CSF formation. Exp Brain Res 1989; 77: 605-610.

74. Liu D, Diorio J , Tannenbaum B, Caldji C, Francis D, Freedman A, Sharma S, Pearson D, Plotsky PM, Meaney MJ . Maternal care, hippocampal glucocorticoid receptors, and hypothalamic-pituitary-adrenal responses to stress. Science 1997; 277: 1659-1662.

75. Liu J, Wang X, Shigenaga MK, Yeo HC, Mori A, Ames BN. Immobilization stress causes oxidative damage of lipid, protein and DNA in the brain or rats. FASEB J 1996; 10: 1532-1538.

76. Lowy MT, Gault L, Yamamoto BK. Adrenalectomy attenuates stress-induced el evations in extracellular glutamate concentrations in the hippocampus. J Neurochem 1993; 61: 19571960.

77. Luine VN, Rentas J, Sterbank L, Beck K. Estradiol effects on rat spatial memory. Soc Neurosci Abstr 1996; 22: No. 547.9-P1387. [abstract].

78. Lupien S, Lecours AR, Lussier I, Schwartz G, Nair NPV, Meaney MJ. Basal cortisol levels and cognitive deficits in human aging. J Neurosci 1994; 14: 2893-2903.

79. Lupien SJ , DeLeon MJ , DeSanti S, Convit A, Tarshish C, Nair NPV, Thakur M, McE wen BS, Hauger RL, Meaney MJ . Cortisol levels during human aging predict hippocampal atrophy and memory deficits. Nature Neurosci 1998; 1: 69-73.

80. Lupien SJ , Gaudreau S, Tchiteya BM, Maheu F, Sharma S, Nair NPV, Hauger RL, McE wen BS, Meaney MJ . Stress-induced ded arative memory impairment in healthy el derly subjectsRelationship to cortisol reactivity. J Clin Endocrinol Metab 1997; 82: 2070-2075.

81. Lupien SJ, McEwen BS. The acute effects of corticosteroids on cognition: Integration of animal and human model studies. Brain Res Rev 1997; 24: 1-27.

82. Maccari S, Piazza PV, Kabbaj M, Barbazanges A, Simon H, LeM oal M. Adoption reverses the long-term impairment in glucocorticoid feedback induced by prenatal stress. J Neurosci 1995; 15: 110-116.

83. Magarinos AM, McE wen BS. Stress-induced atrophy of apical dendrites of hippocampal CA3c neurons: I nvolvement of glucocorticoid secretion and excitatory amino acid receptors. Neuroscience 1995; 69: 89-98.

84. Magarinos AM, McEwen BS. The hippocampal morphology of diabetic rats shows an increased vulnerability to repeated stress. Soc Neurosci 1998. [abstract].

85. Magarinos AM, McE wen BS, Flugge G, Fuchs E. Chronic psychosocial stress causes apical dendritic atrophy of hippocampal CA3 pyramidal neurons in subordinate tree shrews. J Neurosci 1996; 16: 3534-3540.

86. Magarinos AM, Verdugo Garcia J M, McE wen BS. Chronic restraint stress alters synaptic terminal structure in hippocampus. Proc Natl Acad Sci USA 1997; 94: 14002-14008. 
87. Maren S. Properties and mechanisms of long-term synaptic plasticity in the mammalian brain: Relationships to learning and memory. Neurobiol Learning Memory 1995; 63: 1-18.

88. McCord J . Oxygen-derived free radicals in postischemic tissue injury. N Engl J Med 1985; 312: 159-163.

89. McE wen BS. Re-examination of the glucocorticoid cascade hypothesis of stress and aging. In: Swaab D, Hoffman M, Mirmiran R, Ravid F, van Leeuwen F, Eds. Progress in Brain Research. Amsterdam: Elsevier, 1992: 365-383.

90. McEwen BS. Possible mechanisms for atrophy of the human hippocampus. Mol Psychiatr 1997; 2: 255-262.

91. MCE wen BS. Protective and damaging effects of stress mediators. N Engl J Med 1998; 338: 171-179.

92. McE wen BS, Albeck D, Cameron H, Chao HM, Gould E, Hastings N, et al. Stress and the brain: A paradoxical role for adrenal steroids. In: Litwack GD, Ed. Vitamins and Hormones. New York: Academic Press, 1995: 371-402.

93. McE wen BS, Alves SE, Bulloch K, Weiland NG. Ovarian steroids and the brain: implications for cognition and aging. Neurol ogy 1997; 48: S8-S15.

94. McE wen BS, Gould E, Orchinik M, Weiland NG, Woolley CS. Oestrogens and the structural and functional plasticity of neurons: I mplications for memory, ageing and neurodegenerative processes. In: Goode J , Ed. Ciba Foundation Symposium No. 191: The Non-reproductive Actions of Sex Steroids. London: CIBA Found, 1995: 52-73.

95. McE wen BS, Weiss J , Schwartz L. Selective retention of corticosterone by limbic structures in rat brain. Nature 1968; 220: 911-912.

96. Meaney M, Aitken D, Berkel H, Bhatnager S, Sapolsky R. Effect of neonatal handling of age-related impairments associated with the hippocampus. Science 1988; 239: 766-768.

97. Meaney M, Aitken D, Sapolsky R. Thyroid hormones influencethe devel opment of hippocampal glucocorticoid receptors in the rat: a mechanism for the effects of postnatal handling on the development of the adrenocortical stress response. Neuroendocrinology 1987; 45: 278285.

98. Meaney MJ, Tannenbaum B, Francis D, Bhatnagar S, Shanks N, Viau V, O'Donnell D, Plotsky PM. Early environmental programming hypothalamic-pituitary-adrenal responses to stress. Semin Neurosci 1994; 6: 247-259.

99. Miller AH, Spencer R, Pulera M, Kang S, McE wen BS, Stein M. Adrenal steroid receptor activation in rat brain and pituitary following dexamethasone: implications for the dexamethasone suppression test. Biol Psychol 1992; 32: 850-869.

100. Mizoguchi K, Kunishita T, Chui DH, Tabira T. Stress induces neuronal death in the hippocampus of castrated rats. Neurosci Lett 1992; 138: 157-160.

101. Moghaddam B, Boliano ML, Stein-Behrens B, Sapolsky R. Glucocorticoids mediate the stress-induced extracellular accumulation of glutamate. Brain Res 1994; 655: 251-254.

102. Montkowski A, Barden N, Wotjak C, Stec I, Ganster J, Meaney M, Engelmann M, Reul J MHM, Landgraf R, Holsboer F. Long-term antidepressant treatment reduces behavioural deficits in transgenic mice with impaired glucocorticoid receptor function.J Neuroendocrinol 1995; 7: 841-845.

103. Morrison J H, Hof PR. Life and death of neurons in the aging brain. Science 1997; 278: 412-419.

104. Morse J K, Dekosky ST, Scheff SW. Neurotrophic effects of steroids on lesion-induced growth in the hippocampus. Exp Neurol 1992; 118: 47-52.

105. Norris CM, Halpain S, Foster TC. Reversal of age-related alterations in synaptic plasticity by blockade of L-type Ca2+ channels. J Neurosci 1998; 18: 3171-3179.

106. O'N eal MF, Means LW, Poole MC, Hamm RJ . Estrogen affects performance of ovariectomized rats in a two-choice water-escape working memory task. Psychoneuroendocrinol ogy 1996; 21: 51-65. 
107. Orchinik M, Weiland NG, McE wen BS. Adrenal ectomy sel ectively regulates GABAa receptor subunit expression in the hippocampus. Mol Cell Neurosci 1994; 5: 451-458.

108. Paganini-Hill A, Henderson VW. Estrogen deficiency and risk of Alzheimer's Disease in women. AmJ Epidemil 1994; 3: 3-16.

109. Pavlides C, Kimura A, Magarinos AM, McE wen BS. Typel adrenal steroid receptors prolong hippocampal long-term potentiation. NeuroReport 1994; 5: 2673-2677.

110. Pavlides C, Kimura A, Magarinos AM, McE wen BS. Hippocampal homosynaptic long-term depression/depotentiation induced by adrenal steroids. Neuroscience 1995; 68: 379-385.

111. Pavlides C, Ogawa S, Kimura A, McE wen BS. Role of adrenal steroid mineralcorticoid and glucocorticoid receptors in long-term potentiation in the CA1 field of hippocampal slices. Brain Res 1996; 738: 229-235.

112. Pavlides C, WatanabeY, Magarinos AM, McE wen BS. Opposing role of adrenal steroid Type I and Type II receptors in hippocampal long-term potentiation. Neuroscience 1995; 68: 387394.

113. Piazza PV, Marinelli M, J odogne C, Deroche V, Rouge-Pont F, Maccari S, LeM oal M, Simon $\mathrm{H}$. Inhibition of corticosterone synthesis by metyrapone decreases cocaine-induced locomotion and relapse of cocaine self-administration. Brain Res 1994; 658: 259-264.

114. Popov VI, Bocharova LS. Hibernation-induced structural changes in synaptic contacts between mossy fibres and hippocampal pyramidal neurons. Neuroscience 1992; 48: 53-62.

115. Popov VI, Bocharova LS, Bragin AG. Repeated changes of dendritic morphology in the hippocampus of ground squirrels in the course of hibernation. Neuroscience 1992; 48: 45-51.

116. Porter NM, Thibault O, Thibault V, Chen K, Landfield PW. Calcium channel density and hippocampal cell death with age in long-term culture. J Neurosci 1997; 17: 5629-5639.

117. Pouliot wA, Handa RJ, Beck SG. Androgen modulates N-methyl-D-aspartate-mediated depolarization in CA1 hippocampal pyramidal cells. Synapse 1996; 23: 10-19.

118. Prewitt CMF, Herman J P. Hypothalamo-pituitary-adrenocortical regulation following le sions of the central nucleus of the amygdala. Stress 1997; 1: 263-279.

119. Rapp PR, Gallagher M. Preserved neuron number in the hippocampus of aged rats with spatial learning deficits. Proc Natl Acad Sci USA 1996; 93: 9926-9930.

120. Rasmussen T, Schliemann T, Sorensen J C, Zimmer J, West MJ . Memory impaired aged rats: Noloss of principal hippocampal and subicular neurons. Neurobiol Aging 1996; 14: 143-147.

121. Reagan LP, Magarinos AM, McE wen BS. Molecular changes induced by stress in streptozotocin (STZ) diabetic rats. Soc Neurosci 1998. [abstract].

122. Regier DA, Boyd J H, Burke J D, Rae DS, Myers J K, Kramer M, Robbins LN, George LK, Karno M, Locke BZ. One-month prevalence of mental disorders in the U.S. Arch Gen Psychiatr 1988; 45: 977-986.

123. Robinson D, Friedman L, Marcus R, Tinklenberg J , Yesavage J . Estrogen replacement therapy and memory in ol der women.J Am Geriatr Soc 1994; 42: 919-922.

124. Roozendaal B, Kool haas J M, Bohus B. Central amygdaloid involvement in neuroendocrine correlates of conditioned stress responses. J . Neuroendocrinol 1997; 4: 483-489.

125. Rowe W, Steverman A, Walker M, Sharma S, Barden N, Seckl J R, Meaney MJ . Antidepressants restore hypothalamic-pituitary-adrenal feedback function in aged, cognitively impaired rats. Neubiol Aging 1997; 18: 527-533.

126. Sapolsky R. Stress, the aging brain and the mechanisms of neuron death. Cambridge: MIT Press, 1992: 1-423.

127. Sapolsky R, Krey L, M cE wen BS. Glucocorticoid-sensitive hippocampal neurons are involved in terminating the adrenocortical stress response. Proc Natl Acad Sci USA 1984; 81: 6174-6177.

128. Sapolsky R, Krey L, McE wen BS. Prolonged glucocorticoid exposure reduces hippocampal neuron number: I mplications for aging. J Neurosci 1985; 5: 1222-1227.

129. Sapolsky RM. Why stress is bad for your brain. Science 1996; 273: 749-750. 
130. Sapolsky RM, Krey LC, McEwen BS. The neuroendocrinology of stress and aging: The glucocorticoid cascade hypothesis. Endocr Rev 1986; 7: 284-301.

131. Seeman TE, MCE wen BS, Singer BH, Albert MS, Rowe J W. Increase in urinary cortisol excretion and memory declines: MacArthur studies of successful aging. J Clin Endocrinol Metab 1997; 82: 2458-2465.

132. Seeman TE, Robbins RJ . Aging and hypothalamic-pituitary-adrenal response to challenge in humans. Endocr Rev 1994; 15: 233-260.

133. Sheline YI, Wang PW, Gado MH, Csernansky J C, Vannier MW. Hippocampal atrophy in recurrent major depression. Proc Natl Acad Sci USA 1996; 93: 3908-3913.

134. Sherwin BB. Estrogenic effects on memory in women. Ann NY Acad Sci 1994; 743: 213-231.

135. Sherwin BB, Tulandi T. "Add-back" estrogen reverses cognitive deficits induced by a gonadotropin-releasing hormone agonist in women with leiomyomata uteri. J Clin Endocrinol Metab 1996; 81: 2545-2549.

136. Spencer RL, Kim PJ , Kalman BA, Cole MA. Evidence for mineralocorticoid receptor facilitation of glucocorticoid receptor-dependent regulation of hypothalamic-pituitary-adrenal axis activity. Endocrinology 1998; 139: 2718-2726.

137. Spencer RL, Moday HJ , Miller AH. Maintenance of basal ACTH levels of corticosterone and Ru28362, but not aldosterone: Relationship to available Type I and Type II corticosteroid receptor levels in brain and pituitary. Stress 1997; 2: 51-64.

138. Starkman MN, Gebarski SS, Berent S, Schteingart DE. Hippocampal formation volume, memory dysfunction, and cortisol levels in patients with Cushing's Syndrome. Biol.Psychiatr 1992; 32: 756-765.

139. Sugaya K, Chouinard M, Greene R, Robbins M, Personett D, Kent C, Gallagher M, McKinney M. Molecular indices of neuronal and glial plasticity in the hippocampal formation in a rodent model of age-induced spatial learning impairment. J Neurosci 1996; 16: 3427-3443.

140. Tang MX, J acobs D, Stern Y, Marder K, Schofield P, Gurland B, Andrews H, Mayeux R. Effect of oestrogen during menopause on risk and age at onset of Alzheimer's disease. Lancet 1996; 348: 429-432.

141. Uno H, Ross T, Else J, Suleman M, Sapolsky R. Hippocampal damage associated with prolonged and fatal stress in primates. J Neurosci 1989; 9: 1709-1711.

142. Valee M, Mayo W, Dellu F, Le Moal M, Simon H, Maccari S. Prenatal stress induces high anxiety and postnatal handling induces low anxiety in adult offspring: Correlation with stress-induced corticosterone secretion.J Neurosci 1997; 17: 2626-2636.

143. Vallee M, Mayo W, Maccari S, Le Moal M, Simon H. Long-term effects of prenatal stress and handling on metabolic parameters: Relationship to corticosterone secretion response. Brain Res 1996; 712: 287-292.

144. Van Cauter E, Leproult R, Kupfer DJ. Effects of gender and age on the levels and circadian rhythmicity of plasma cortisol. J Clin Endocrinol Metab 1996; 81: 2468-2473.

145. Watanabe $Y$, Weiland NG, McEwen BS. Effects of adrenal steroid manipulations and repeated restraint stress on dynorphin mRNA levels and excitatory amino acid receptor binding in hippocampus. Brain Res 1995; 680: 217-225.

146. Weiland NG. Estradiol selectively regulates agonist binding sites on the N-methyl-Daspartate receptor complex in the CA1 region of the hippocampus. Endocrinology 1992; 131: 662-668.

147. Weiland NG, Orchinik M, McEwen BS. Corticosterone regulates mRNA levels of specific subunits of the NMDA receptor in the hippocampus but not in cortex of rats. Soc Neurosci Abstr 1995; 21: No. 207.12, 502.

148. Weiland NG, Orchinik M, Tanapat P. Chronic corticosterone treatment induces parallel changes in N-methyl-D-aspartate receptor subunit messenger RNA levels and antagonist binding sites in the hippocampus. Neuroscience 1997; 78: 653-662. 
149. Wilkinson CW, Peskind ER, Raskind MA. Decreased hypothalamo-pituitary-adrenal axis sensitivity to cortisol feedback inhibition in human aging. Neuroendocrinology 1997; 65: 79-90.

150. Woolley C, Gould E, Frankfurt M, McE wen BS. Naturally occurring fluctuation in dendritic spine density on adult hippocampal pyramidal neurons. J Neurosci 1990; 10: 4035-4039.

151. Woolley C, McEwen BS. Estradiol regulates hippocampal dendritic spine density via an N-methyl-D-aspartate receptor dependent mechanism. J Neurosci 1994; 14: 7680-7687.

152. Wool ley CS, Weiland NG, McE wen BS, Schwartzkroin PA. Estradiol increases the sensitivity of hippocampal CA1 pyramidal cells to NMDA receptor-mediated synaptic input: Correlation with dendritic spine density. J Neurosci 1997; 17: 1848- 1859.

153. Xu H, Gouras GK, Greenfield J P, Vincent B, Naslund J , Mazzarelli L, Fried G, J ovanovic J N, Seeger M, Relkin NR, Liao F, Checler F, et al. Estrogen reduces neuronal generation of Alzheimer b-amyloid peptides. Nature Med 1998; 4: 447-451.

154. Young EA, Haskett RF, Grunhaus L, Pande A, Weinberg M, Watson SJ , Akil H. Increased evening activation of the hypothalamic-pituitary-adrenal axis in depressed patients. Arch Gen Psychiatr 1994;51: 701-707.

155. Zhang W, Mundy WR, Thai L, Hudson PM, Gallagher M, Tilson HA, Hong J S. Decreased glutamate release correlates with elevated dynorphin content in the hippocampus of aged rats with spatial learning deficits. Hippocampus 1991; 1: 391-398. 